
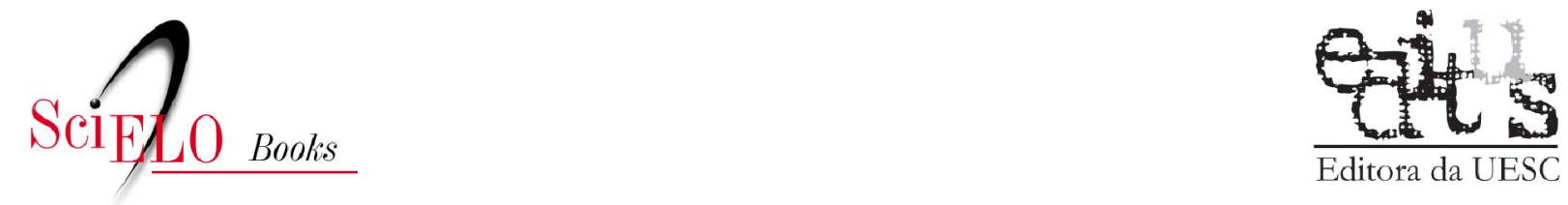

Editora da UESC

\title{
13 - Grupos tróficos e guildas em formigas poneromorfas
}

\author{
Rogério R. Silva \\ Rogério Silvestre \\ Carlos R. F. Brandão \\ Maria S. C. Morini \\ Jacques H. C. Delabie
}

SciELO Books / SciELO Livros / SciELO Libros

SILVA, RR., et al. Grupos tróficos e guildas em formigas poneromorfas. In: DELABIE, JHC., et al., orgs. As formigas poneromorfas do Brasil [online]. Ilhéus, BA: Editus, 2015, pp. 163-179. ISBN 97885-7455-441-9. Available from SciELO Books $<$ http://books.scielo.org $>$.

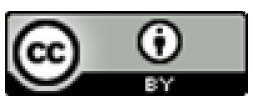

All the contents of this work, except where otherwise noted, is licensed under a Creative Commons Attribution 4.0 International license.

Todo o conteúdo deste trabalho, exceto quando houver ressalva, é publicado sob a licença $\underline{\text { Creative Commons }}$ Atribição 4.0.

Todo el contenido de esta obra, excepto donde se indique lo contrario, está bajo licencia de la licencia $\underline{\text { Creative }}$ Commons Reconocimento 4.0. 


\title{
13
}

\section{Grupos tróficos e guildas em formigas poneromorfas}

\author{
Rogério R. Silva, Rogério Silvestre, Carlos R.F. Brandão, \\ Maria S.C. Morini, Jacques H.C. Delabie
}

\section{Resumo}

As formigas poneromorfas podem representar cerca de $25 \%$ da diversidade local de Formicidae em ambientes tropicais. Em princípio, a teoria ecológica prevê regras de formação de assembleias que definem a contribuição relativa de grupos de espécies ao conjunto local de espécies de formigas, sendo que competição e filtros ambientais são importantes componentes para explicar esta proporcionalidade em termos de grupos funcionais. A forma de utilização dos recursos, a co-ocorrência de espécies que compartilham requisitos ecológicos e a diversidade morfológica são características que podem ser submetidas a análises que permitem desvendarmos as leis que estruturam as comunidades. Neste capítulo, classificamos funcionalmente as formigas poneromorfas e discutimos o papel deste grupo na ecologia de comunidades de formigas. Nosso objetivo é descrever a estruturação das formigas poneromorfas em guildas usando uma abordagem evolutiva, construída a partir do reconhecimento de grupos taxonômicos relacionados evolutivamente e ecologicamente, enquanto discutimos a distribuição e importância de caracteres funcionais e biológicos. Para atingir esse objetivo, tratamos inicialmente de aspectos conceituais sobre o tema, incluindo nicho multidimensional, guildas e suas subdivisões, seguidos de uma revisão de trabalhos sobre organização funcional de formigas na Região Neotropical.

SILVA, Rogério R.; SILVESTRE, Rogério; BRANDÃO, Carlos R. F.; MORINI, Maria S. C.; DELABIE, Jacques H. C. Grupos tróficos e guildas em formigas poneromorfas. In: DELABIE, Jacques H. C. et al. As formigas poneromorfas do Brasil. Ilhéus: Editus, 2015. p. 163-179. 
Trophic groups and guilds of poneromorph ants - In tropical environments poneromorph ants are an important component of the taxonomic and functional diversity of local ant communities. In this chapter we present a functional classification of poneromorph ants, reviewing the role of this group in the ecology of the Neotropical region. A description of the guild structure based on an evolutionary approach is presented, discussing the importance of functional and biological traits of poneromorph ants. To achieve this goal, we deal with conceptual aspects of guilds and functional groups, and also the multidimensional niche, followed by a review of studies on functional organization of ants in the Neotropics. Macroguilds are defined as a group of species that share general ecological variables, such as foraging habits, nesting sites and trophic position. Macroguilds can be divided into smaller compartments called microguilds if a higher number of variables is considered in classification analyses. We use trophic position, foraging, nesting sites, behaviour and morphological traits to define seven poneromorph macroguilds: (1) small-size in the leaf-litter; (2) large-size epigaeic; (3) arboreal poneromorph species; (4) with long mandibles; (5) specialized and cryptic; (6) with legionary behavior; and (7) ectaheteromorph generalist predators (Ectatomminae; Heteroponerinae). Our proposed scheme includes data on ecology, life history traits and morphology to delimit macroguilds and is analogous to the functional trait approach. Use of this conceptual model allows a description of ant fauna organization in different areas of the Neotropical Region in an elaborate and appropriate format, enabling comparisons and predictions on community structure to be made.

\section{Conceituação de Nicho, Grupos Tróficos, Guildas e Grupos Funcionais}

O termo nicho ecológico é de fundamental importância em ecologia porque se relaciona a várias questões com impacto na estruturação de comunidades, incluindo uso de recursos, diversidade em uma escala macro-geográfica e muitos aspectos que influenciam a composição e a estrutura das comunidades (MCGILL et al., 2006). O conceito de nicho foi formalizado por George Evelyn Hutchinson (1957) como um espaço abstrato ndimensional com os eixos representados por variáveis biológicas importantes (bióticas e abióticas) e independentes (sendo o nicho definido como um hipervolume). Ainda que muitas modificações na ideia original tenham sido propostas (CHASE; LEIBOLD, 2003), as definições atuais representam o nicho por um espaço multidimensional (NEWSOME et al., 2007; KEARNEY et al., 2010). Mais recentemente, avanços computacionais sugerem que o uso de estimadores kernel de densidade multidimensional pode ser uma abordagem particularmente apropriada para descrever o nicho. Tais estimadores quantificam o volume do nicho em um espaço n-dimensional, representando de forma acurada áreas não ocupadas do espaço ou espaços que não fazem parte do hipervolume (geometria e topologia do espaço) (BLONDER et al., 2014). O uso de atributos funcionais das espécies pode ser especialmente adequado para a descrição de modelos de nicho (KEARNEY et al., 2010).

As múltiplas dimensões do nicho ecológico de uma espécie podem ser, de forma geral, divididas em dois conjuntos: um componente trófico (relativo a recursos) e um componente ambiental (relativo a condições) (HUTCHINSON, 1957; SOBERÓN; NAKAMURA, 2009; COLWELL; RANGEL, 2009; KEARNEY et al., 2010). Um método para quantificar o componente trófico (recursos que animais usam) é através do uso de isótopos estáveis. A razão ${ }^{15} \mathrm{~N} /{ }^{14} \mathrm{~N}$ é usada como marcador trófico porque essa relação aumenta em cerca de 3\% a 5\% a cada nível trófico; assim a assinatura isotópica dos tecidos animais de consumidores é fortemente relacionado à dieta alimentar (NEWSOME et al., 2007; JACKSON et al., 2011).

Grupos tróficos em formigas são comumente descritos como fungívoros (subdivididos em herbívoros, se usam matéria vegetal fresca para cultivo do fungo ou, detritívoros, se usam insetos mortos ou fezes de animais como substrato para o fungo), ou carnívoros e onívoros (aqueles que 
participam de mais de um nível trófico) (KASPARI, 2001). Muitas espécies de solo utilizam ainda diásporos (sementes, frutos ou infrutescências) e alguns frutos podem complementar o consumo de lipídeos em poneromorfas primariamente carnívoras (PASSOS; OLIVEIRA, 2004).

Espécies arborícolas derivam frações significantes de nitrogênio da herbivoria e podem ser classificadas operacionalmente em dois grupos funcionais: (1) forrageadores de exsudatos de Hemiptera trofobiontes (honeydew) e (2) forrageadores de folhas, buscando continuamente na lâmina foliar recursos dispersos como nectários extraflorais, secreções de plantas, honeydew descartado, secreções de fungos, matéria particulada como pólen e esporos de fungos, fezes de vertebrados, presas e microorganismos (DAVIDSON et al., 2003; DAVIDSON, 2005).

O termo guilda é bastante antigo e tem ampla gama de significados, tendo sido inspirado pelo conceito medieval de um grupo de operários da mesma legião e para designar corporações de ofícios, como, por exemplo, a guilda de cavaleiros andantes e a guilda de donos de moinhos, sem implicação de cooperação, mas com sobreposição de função. A palavra foi primeiramente usada por geógrafos e ecólogos de plantas como uma tradução de "Gennossenschaften", como na edição inglesa de Schimper (1903), para designar quatro grupos de plantas que dependem de outras plantas (lianas, epífitas, saprófitas e parasitas).

Root (1967) foi o primeiro zoólogo a usar este termo, redefinindo-o como "um grupo de espécies que exploram as mesmas classes de recursos ambientais de maneira similar", considerando-o como "o mais evocativo e sucinto para grupos de espécies, que têm padrões semelhantes de exploração de recursos". Nesse sentido, o conjunto de guildas de uma comunidade seria moldado pelas adaptações a uma mesma classe de recursos e por competição. Os elementos chaves para essa definição são: (1) que as espécies sejam sintópicas e (2) que a similaridade entre as espécies seja descrita pelo uso dos recursos (e não pela taxonomia), sendo interações competitivas especialmente importantes entre espécies da mesma guilda (WIENS, 1989).

$\mathrm{O}$ termo adquiriu múltiplos significados e foi usado para descrever grupos de espécies colonizando ou invadindo uma nova área, para designar um nível trófico, e para grupos de espécies características de determinados hábitats ou estágios sucessionais. Além disso, vários outros termos paralelos têm sido usados para descrever grupos ecológicos de espécies, como grupos funcionais, tipos funcionais, síndrome adaptativa, liga, guilda funcional, guildas operacionais, espécies tróficas, módulo, estratégia, grupo efeito, grupo resposta e grupo ecológico (BLAUM et al., 2011; DE PAULA, 2013). A distinção entre esses termos não é consistente, sendo utilizados por diferentes autores para descrever diferentes grupos de espécies organizadas de várias maneiras (PIANKA, 1980; WILSON, 1999); além disso, são usados muitas vezes como sinônimos de guilda (SIMBERLOFF; DAYAN, 1991).

Wilson (1999) propõe dois tipos conceituais de guildas: a guildas alfa e beta. A distinção básica é que as guildas beta são baseadas em classificações que usam condições ambientais ou fatores independentes de competição (temperatura, umidade relativa). No caso, espécies poderiam ser caracterizadas como, por exemplo, árticas, termófilas, entre outros grupos. Guildas alfa são determinadas pelos recursos que um organismo pode utilizar em seu ambiente, diminuindo a quantidade disponível a outros organismos e originando potencial competição (por exemplo, predadoras, nectarívoras, detritívoras, onívoras). Portanto, as guildas beta são relacionadas a grupos de espécies com distribuição geográfica e outras características do ambiente ligadas ao conceito Grinneliano de nicho (GRINNELL, 1917). Por sua vez, as guildas alfa são definidas sensu Root (1967) e Pianka (1980) como grupos de espécies que usam recursos de forma similar, relacionado ao conceito Eltoniano de nicho (ELTON, 1927). Esses dois modelos, Grinneliano e Eltoniano, são formas opostas de definição de nicho e de se enxergar a função de uma espécie no ecossistema, mas de certa forma estão relacionadas entre si.

Ainda, podemos definir guildas em termos de amplitude do nível de tolerância fisiológica. Nos ecossistemas, as populações ou comunidades são o resultado de adaptações a um complexo de fatores ambientais e biológicos ao longo da sua evolução. Chamamos de guildas euripotentes aquelas formadas por espécies com uma tolerância ambiental de grande amplitude (como as espécies generalistas) e guildas estenopotentes, formadas por espécies que têm estreita amplitude de tolerância ambiental (como as especialistas). De fato, estudos ecológicos empregando abordagem fisiológica e usando formigas como organismo modelo têm apontado que o uso de atributos fisiológicos incluem nas análises um importante componente dos sistemas 
biológicos, permitindo modelar melhor o efeito de mudanças ambientais em estudos de bioindicação (DIAMOND et al., 2012).

Blondel (2003) apresenta de forma clara as diferenças conceituais, características e atributos que diferenciam guildas de grupos funcionais. $\mathrm{O}$ termo guilda refere-se somente às relações interespecíficas para aquisição de recursos (componente trófico); por sua vez, grupo funcional refere-se ao potencial de funções que as espécies podem apresentar nos ecossistemas (sem qualquer relação com competição), como a participação nos ciclos biogeoquímicos, a resistência à invasão ou ao fogo, a defesa contra herbivoria, polinização, dispersão de sementes ou qualquer processo físico (BLAUM et al., 2011).

Teoricamente um grupo funcional pode conter mais de uma guilda, enquanto uma guilda não pode agrupar mais de um grupo funcional. Como exemplo didático, considere-se as espécies consumidoras de sementes, nas quais estão incluídas aves, primatas, roedores, besouros e formigas, entre outros; todos têm a mesma função trófica, caracterizando um grupo funcional "consumidores de sementes". No entanto, a forma de utilização deste recurso, que inclui tamanhos diferentes de sementes consumidas, horários diferentes de forrageamento e estratégias diferentes de alimentação, revela diferentes guildas. A definição de uma guilda é feita considerando um gradiente de variáveis que vai desde agrupamentos montados a partir de poucos atributos ecológicos envolvidos, 0 que se aproxima do conceito de grupo funcional, até um grande número de variáveis ecológicas envolvidas, o que se aproxima da definição de nicho ecológico (Figura 13.1).

Figura 13.1 - Ilustração do espaço morfo-funcional das formigas poneromorfas. O espaço contém 20 espécies, delimitadas em quatro guildas. Espécies não classificadas nas guildas $(A, B, C$ ou D) podem representar guildas monoespecíficas (especialização extrema) ou podem representar uma guilda generalista dentro de um espaço morfo-funcional maior. Os limites do espaço são determinados objetivamente por técnicas de classificação, mas também podem ser arbitrários de acordo com o nível de análise. Guilda descreve similaridade no uso de recurso e competição sem considerar processos ou funções; grupo funcional em ecologia animal se refere a espécies que performam funções ou serviços ecossistêmicos sem qualquer relação com competição (Blondel 2003). Macroguildas são definidas como um grupo de espécies que compartilham variáveis ecológicas gerais, como por exemplo, local de forrageamento, local de nidificação e nível trófico. Macroguildas podem ser divididas em outros compartimentos se forem consideradas um número maior de variáveis ecológicas na análise (o que depende da questão ecológica do trabalho).

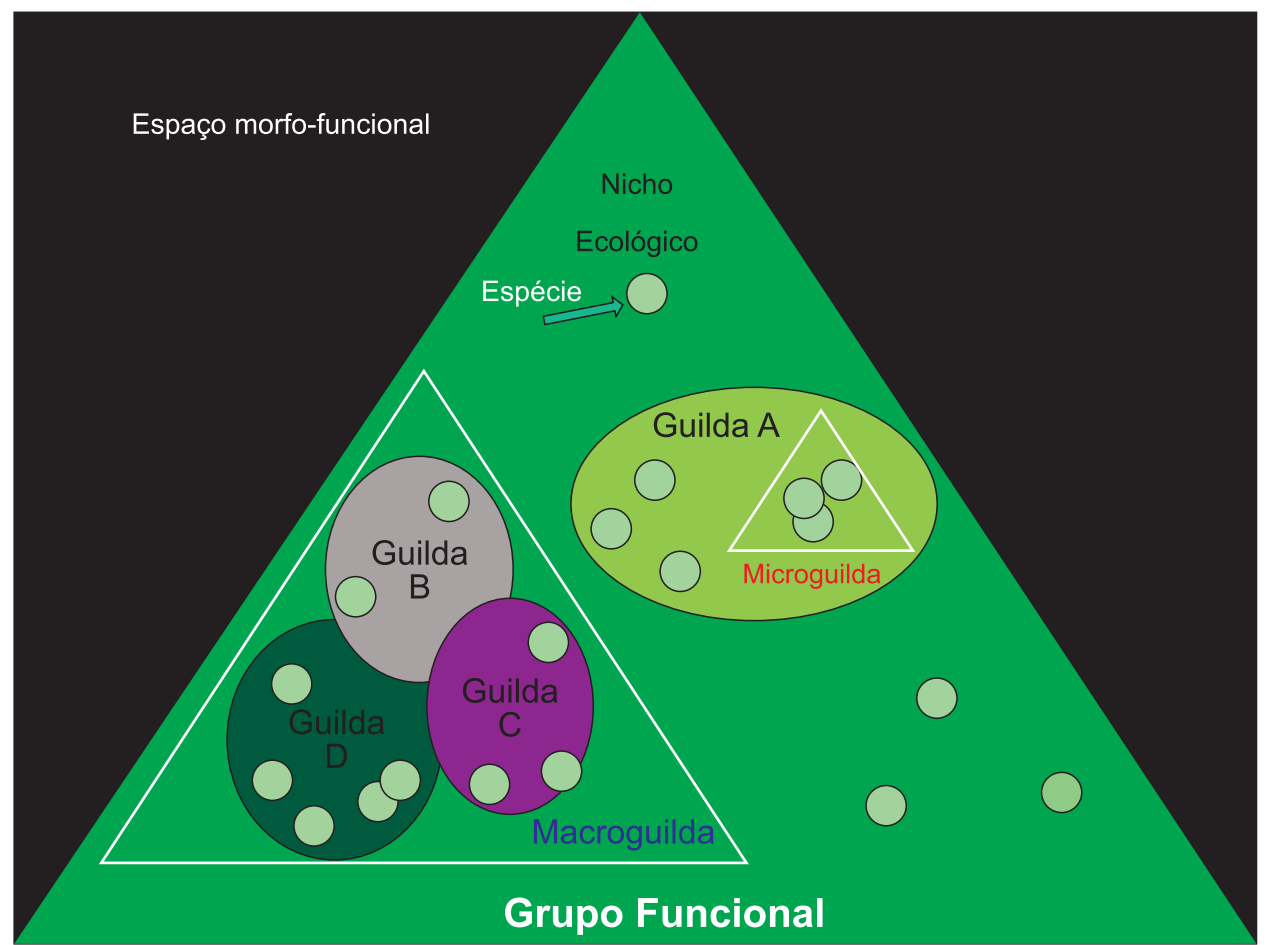


A aplicação do conceito de guildas é considerada especialmente útil em estudos ecológicos porque guildas agrupam organismos que têm significante sobreposição nos requerimentos do nicho e compartilham recursos (JAKSIC, 1981; PIANKA, 1980). Agrupar organismos em guildas facilita a descrição de parte da estrutura das comunidades e pode ser ferramenta importante no delineamento comparativo de diferentes comunidades (GOTELLI; GRAVES, 1996).

A maioria dos estudos realizados até agora não utiliza métodos quantitativos para separar grupos de espécies com ecologia similar e a compreensão dos processos ecológicos envolvidos é, na melhor das hipóteses, parcial, focando apenas nos aspectos mais básicos das interações ecológicas, como as relações tróficas. Silvestre e colaboradores (2003) desenvolveram uma forma de categorização da comunidade de formigas na forma de guildas, utilizando para tal finalidade o maior número de variáveis ecológicas possíveis de serem observadas em campo, como localização do ninho, período de forrageamento, tipo de recrutamento, tamanho, agilidade, preferência alimentar, etc. As categorias dentro de cada variável ecológica são utilizadas para análise de agrupamento, onde as guildas são reveladas por distância entre os agrupamentos. Métodos objetivos de descrição dos agrupamentos também podem ser utilizados (JAKSIC; MEDEL, 1990; FARIAS; JAKSIC, 2006). Silva e Brandão (2010) desenvolveram uma forma de organização funcional da comunidade de formigas a partir de atributos morfológicos selecionados das espécies.

A utilização deste modelo de guildas na análise de diferentes comunidades promove um avanço na interpretação funcional dos ecossistemas terrestres, uma vez que tais comparações têm sido feitas até agora baseando-se exclusivamente em listas de espécies. Temos em mãos, agora, uma ferramenta que nos permite realizar comparações entre os modelos estruturais de cada ambiente, revelando, desta forma, diferenças na ecologia das comunidades observadas. Como a estrutura das guildas resulta da ação combinada de vários fatores atuantes no sistema, a sua caracterização nos permite aprofundar os estudos relativos a quais compartimentos são influenciados pela atividade de cada guilda. Com isso é possível averiguar as alterações da comunidade em função da modificação da composição das guildas presentes, indicando, desta maneira, os alicerces nos quais estão sendo equilibradas as relações interespecíficas.

\section{Características biológicas, morfológicas e funcionais de poneromorfas para sua classificação em guildas}

As formigas poneromorfas incluem representantes de diversas subfamílias, distribuídas em dois grandes clados da história evolutiva de formigas, (1) o clado Poneroide, representado por Proceratiinae (133 espécies), Amblyoponinae (126 espécies), Ponerinae (1.295) e Paraponerinae (1 espécie) e, (2) o clado Formicoide representado por Heteroponerinae (24 espécies) e Ectatomminae (263 espécies) (BRADY et al., 2006; FERNÁNDEZ; ARIAS-PENNA, 2008).

Poneromorfas são predadoras por excelência (às vezes são chamadas "Formigas Caçadoras", vide JIMÉNEZ et al., 2008), mas generalistas por convergência, e sua diversidade está intimamente relacionada com a diversidade de outros grupos de invertebrados terrestres. Apresentam uma imensa diversidade morfológica, comportamental e, em consequência, ecológica. Considerando a diversidade de formas em poneromorfas (tamanho, forma da mandíbula, esculturação, projeções, cor, pilosidade), a diversidade morfológica deste grupo pode representar uma significativa proporção do espaço morfológico da fauna de formigas neotropicais. De forma semelhante, a intensa participação deste grupo de organismos como predadores, visitantes de secreções açucaradas na vegetação, na construção de ninhos no solo, na serapilheira e na vegetação e na dispersão de frutos e galhos finos na serapilheira sugere uma importante atuação em processos funcionais dos ecossistemas.

As espécies relativamente grandes $(>1 \mathrm{~cm})$ coletam pequenos invertebrados como insetos, moluscos, crustáceos, diplópodes e anelídeos; as de tamanho médio $(0,5-1 \mathrm{~cm})$ capturam cupins e larvas de coleópteros, e as pequenas $(<5 \mathrm{~mm})$ capturam ovos de colêmbolos, estafilinídeos e micro aracnídeos. Além de caçadoras, essas formigas também são capazes de visitar flores, explorar nectários extraflorais, como Ectatomma tuberculatum e E. brunneum (WEBER, 1946), obter honeydew de membracídeos, capturar óleos vegetais e resinas, visitar carcaças de vertebrados em estágios iniciais de decomposição, comer frutos podres, fungos em fezes de animais e no interior de colônias cultivadoras de fungos (Attini); ainda, coletam toda sorte de insetos mortos após uma chuva tropical. 
O agrupamento de formigas poneromorfas compreende espécies com estratégia de forrageamento solitário, com poucas espécies realizando caça em grupo como Leptogenys, Simopelta e algumas espécies de Neoponera; colônias com número reduzido a médio de indivíduos $(<50)$ e capacidade de recrutamento limitada ao tandem running, que pode ser "compensado" pelas habilidades cognitivas espaciais de orientação que estas formigas possuem; além de processarem um grande volume de recursos consumidos per capita, o que permite a elas manter interações e sobreposição de utilização de recursos com outras espécies de formigas sem que a competição seja um fator de exclusão na comunidade. Embora exista sobreposição do nicho espacial e trófico com outras espécies, os poneromorfos exploram uma fatia particular do nicho multidimensional a partir de situações e características diversificadas, como um complexo conjunto de glândulas dermais (MORGAN et al., 2003) e a produção de intercastas, ou "gamergates", capazes de substituir funcionalmente a fêmea reprodutora, em geral única, além de operárias que também colocam ovos (PEETERS, 2012).

As formigas poneromorfas podem ser separadas em dois grandes grupos funcionais quanto ao substrato em que vivem e forrageiam (estratificação do hábitat), epigeicas e hipogeicas. Pelo menos sete macroguildas distintas são identificadas pelas diferentes formas de ocupação do nicho: (1) poneríneos pequenos de serapilheira, (2) poneríneos grandes epigeicos, (3) espécies arborícolas, (4) poneríneos com mandíbula longa, (5) poneríneos crípticos especializados, (6) poneríneos com biologia nômade e (7) ectaheteromorfos predadores generalistas. Essas macroguildas podem ser desmembradas em um número maior de grupos se forem consideradas um número maior de variáveis ecológicas na análise para se definir os agrupamentos. Duas formas de análise de grupos são empregadas na classificação de guildas em poneromorfas, a que utiliza variáveis categóricas ou a que adota variáveis contínuas. A primeira forma é mais relacionada ao uso do recurso, onde os grupos são teoricamente separados de forma arbitrária e a segunda considera medidas de dispersão de pontos, como a morfometria, por exemplo.

As características biológicas e funcionais consideradas em conjunto para descrever as guildas de formigas poneromorfas podem ser encontradas na Tabela 13.I.

\section{Guildas e evolução de poneromorfas}

Da mesma forma que o grupo das poneromorfas não é considerado um agrupamento monofilético (BRADY et al., 2006), não devemos considerar o escopo de papéis desempenhados por estas formigas como representando um único bloco funcional. A caracterização deste grupo como formigas predadoras, ou formigas caçadoras, gera uma ideia de uniformidade comportamental que limita o universo funcional desempenhado por elas. A concepção aqui sugerida é que essas formigas constituem diferentes guildas e a exemplo das novidades taxonômicas que desmembram gêneros tradicionalmente aceitos como uniformes, outros papéis devem ser atribuídos a este conjunto de espécies. Mais ainda, o clado Poneroide, que apresenta relativamente maior consistência filogenética (MOREAU et al., 2006) é, todavia, o grupo que abrange o maior número de agrupamentos funcionais distintos.

Sob a perspectiva de nichos evolutivos (HOLT, 2009), um grupo natural de espécies pode ser descrito como um nicho-clado, para o qual podemos imaginar vários cenários, (i) espécies que mostram uma variação geográfica entre nichos de populações locais; (ii) espécies que ocupam áreas do espaço nicho-clado vagando dentro de um espaço delimitado; (iii) um nicho aninhado de um clado, com espécies especialistas com descendência de ancestrais generalistas e (iv) radiação adaptativa de um ancestral especialista, com o clado coletivamente ocupando um espaço de nicho muito maior do que o representado por cada espécie, individualmente.

A exemplo da evolução do consenso taxonômico de formigas poneromorfas (BRADY et al., 2006), o mesmo deve acontecer no consenso ecológico; ou seja, a subdivisão do grupo funcional "Formigas Caçadoras" em um maior número de guildas expressando com mais fidelidade as diferenças e semelhanças no papel ecológico desempenhado por estas espécies.

Apresentamos a seguir uma classificação de guildas de formigas poneromorfas, a partir de propostas anteriores que empregaram diferentes abordagens (DELABIE et al., 2000; SILVESTRE et al., 2003; BRANDÃO et al., 2009, 2012; SILVA; BRANDÃO, 2010, 2014). A análise tem como referência os componentes do nicho apresentados no item acima. Nosso objetivo é apresentar uma classificação atualizada, simples e operacional para o uso de 
Tabela 13.I - Lista de atributos morfológicos, comportamentais ou biológicos que podem ser categorizados para delimitação das macroguildas em poneromorfas. Observações: para formas de forrageamento ver Lanan (2014). Informações sobre parasitas sociais extraídas de Hora et al. (2005) e Feitosa et al. (2008).

\begin{tabular}{|c|c|c|}
\hline \multicolumn{2}{|c|}{ Atributos } & \multirow{2}{*}{$\begin{array}{l}\text { Caracterização } \\
\text { predadoras de invertebrados terrestres e pequenos } \\
\text { vertebrados. }\end{array}$} \\
\hline Categorias tróficas & Carnívoras & \\
\hline & Nectarívoras & $\begin{array}{l}\text { predominantemente associadas à presença de substâncias } \\
\text { açucaradas na vegetação. }\end{array}$ \\
\hline & Detritívoras & coletam carcaças de animais mortos e fezes de vertebrados. \\
\hline & Onívoras & utilizam dois ou mais recursos listados acima. \\
\hline \multirow[t]{6}{*}{ Local de forrageamento } & Especialista de habitat & $\begin{array}{l}\text { habitam ninhos de cupins ou associam-se a outros } \\
\text { organismos dentro do solo. }\end{array}$ \\
\hline & Hipogeicas & forrageiam nos interstícios da serapilheira. \\
\hline & Subterrâneos & forrageiam exclusivamente no interior do solo. \\
\hline & Epigeicas & forrageiam na superfície do solo ou acima da serapilheira. \\
\hline & $\begin{array}{l}\text { Vegetação: herbáceas e } \\
\text { arbustivas }\end{array}$ & forrageiam em plantas do sub-bosque. \\
\hline & Vegetação: dossel & forrageiam na vegetação que forma o dossel. \\
\hline \multirow[t]{7}{*}{ Localização do ninho } & Vegetação & em partes vivas ou mortas de plantas, especialmente galhos. \\
\hline & Bromélia & em epífitas (terrestres ou sobre a vegetação). \\
\hline & Tronco/galho & $\begin{array}{l}\text { em troncos/galhos dispersos no chão, em processo de } \\
\text { decomposição. }\end{array}$ \\
\hline & Serapilheira & exclusivamente nos interstícios da serapilheira. \\
\hline & Sob pedra & sob pedras. \\
\hline & Em material alóctone & $\begin{array}{l}\text { ninhos em produtos de invertebrados terrestres, como } \\
\text { conchas de gastrópodes. }\end{array}$ \\
\hline & Subterrâneo & abaixo da camada superficial do solo. \\
\hline \multirow[t]{5}{*}{$\begin{array}{l}\text { Comportamental: modo } \\
\text { de forrageamento }\end{array}$} & Patrulheiras & $\begin{array}{l}\text { patrulham uma porção do território da colônia escolhida } \\
\text { aleatoriamente em busca ativa de alimento. }\end{array}$ \\
\hline & Focais & usam trilhas pré-definidas para procurar alimento. \\
\hline & Crípticas & $\begin{array}{l}\text { movimentos lentos e comportamentos especializados para } \\
\text { predar invertebrados na serapilheira (frequentemente associados } \\
\text { a coloração críptica e estruturas especiais para camuflagem). }\end{array}$ \\
\hline & Nômades & $\begin{array}{l}\text { espécies que forrageiam em colunas e que frequentemente } \\
\text { alteram a localização do acampamento temporário } \\
\text { (bivaque). }\end{array}$ \\
\hline & Parasitas & $\begin{array}{l}\text { parasitas sociais conhecidas do gênero Ectatomma } \\
\text { apresentam "microgines" que concentram esforços } \\
\text { reprodutivos na produção de rainhas e machos, } \\
\text { geneticamente distintos e reprodutivamente isolados de } \\
\text { seus hospedeiros. }\end{array}$ \\
\hline \multirow{4}{*}{$\begin{array}{l}\text { Comportamental: modo } \\
\text { de recrutamento }\end{array}$} & Solitário & buscam recurso alimentar de forma isolada, solitariamente. \\
\hline & Tandem running & $\begin{array}{l}\text { após descobrir o recurso alimentar, retornam ao ninho e } \\
\text { acompanham outra operária até a fonte (somente uma } \\
\text { operária é recrutada a cada vez). }\end{array}$ \\
\hline & Parcial & $\begin{array}{l}\text { pequeno número de operárias é recrutado até a fonte } \\
\text { alimentar (de duas a dezenas de operárias). }\end{array}$ \\
\hline & Massivo & $\begin{array}{l}\text { grande proporção da população de forrageadoras é } \\
\text { recrutada. }\end{array}$ \\
\hline \multirow{3}{*}{$\begin{array}{l}\text { Velocidade (metros/ } \\
\text { segundo): medida relativa } \\
\text { das operárias forrageando } \\
\text { (estado normal, sem } \\
\text { estresse) }\end{array}$} & Baixa & $\begin{array}{l}\text { Tempo superior a } 60 \text { segundos para percorrer } 1 \mathrm{~m} \text { (em geral, } \\
\text { espécies hipogeicas, vivendo dentro da serapilheira). }\end{array}$ \\
\hline & Média & $\begin{array}{l}\text { Percorre } 1 \text { m entre } 20 \text { e } 60 \text { segundos. Operárias com } \\
\text { velocidade intermediária, chegando no recurso alimentar } \\
\text { após o grupo que tem alta agilidade (muitas vezes espécies } \\
\text { dominantes, agressivas, com recrutamento massivo). }\end{array}$ \\
\hline & Alta & $\begin{array}{l}\text { Percorre } 1 \mathrm{~m} \text { entre } 10 \text { e } 20 \text { segundos, aproximadamente. } \\
\text { Operárias com alta agilidade, chegando rapidamente } \\
\text { no recurso alimentar (em geral, oportunistas, exploram } \\
\text { o recurso até a chegada das espécies comportalmente } \\
\text { dominantes). }\end{array}$ \\
\hline
\end{tabular}




\begin{tabular}{|c|c|c|}
\hline \multicolumn{2}{|c|}{ Atributos } & \multirow{2}{*}{$\begin{array}{l}\text { Caracterização } \\
\text { maior comprimento ao longo do eixo maior dos olhos, em } \\
\text { geral ligando as margens inferior e superior. }\end{array}$} \\
\hline Variáveis morfológicas & Tamanho de olho & \\
\hline & Projeções corporais & $\begin{array}{l}\text { presença de espinhos e outras projeções na cabeça, tronco e } \\
\text { pecíolo. }\end{array}$ \\
\hline & Tamanho da mandíbula & $\begin{array}{l}\text { entre um ponto médio da linha imaginária que une a borda } \\
\text { externa das bases da mandíbula e o ponto mais distal do } \\
\text { dente apical. }\end{array}$ \\
\hline & $\begin{array}{l}\text { Número de dentes na } \\
\text { mandíbula }\end{array}$ & $\begin{array}{l}\text { número de dentes localizados na região mastigatória (região } \\
\text { interna). }\end{array}$ \\
\hline & $\begin{array}{l}\text { Tamanho do corpo } \\
\text { (Diagonal de Weber) }\end{array}$ & $\begin{array}{l}\text { comprimento do mesossoma, em vista lateral, tomada ao } \\
\text { longo do eixo que liga o ponto médio da curva ascendente } \\
\text { do pronoto até o ângulo póstero-inferior da metapleura. }\end{array}$ \\
\hline & Estruturas especializadas & $\begin{array}{l}\text { presença de glândulas especializadas no corpo e apêndices } \\
\text { das operárias. }\end{array}$ \\
\hline
\end{tabular}

guildas de poneromorfas em estudos de estrutura de comunidades, incluindo as respostas de formigas às alterações ambientais e o monitoramento da fauna de formigas. Informações gerais sobre morfologia e biologia das guildas foram apresentadas em Brandão e colaboradores $(2009,2012)$. Considerando a diversidade morfológica em formigas poneromorfas e a ausência de informações sobre história natural para um grande número de espécies (especialmente de tamanho de corpo pequeno como Hypoponera, Gnamptogenys e Neoponera), reconhecemos que estudos sobre seleção de habitat em macro e microescala são ainda necessários para uma melhor compreensão da distribuição das espécies nas macroguildas.

As seguintes macroguildas de formigas poneromorfas são reconhecidas:

1 Poneríneos pequenos, generalistas, de baixa agilidade vivendo na serapilheira

Incluímos aqui espécies de Belonopelta, Hypoponera (Ponerinae), algumas Gnamptogenys (Ectatomminae) e algumas Heteroponera (Heteroponerinae), como H. microps e H. mayri. A morfologia indica claramente uma adaptação ao modo de vida críptico, caracterizada pela redução do tamanho corporal, do número de omatídeos dos olhos compostos e das projeções corporais. A maioria das espécies de Hypoponera está incluída nesta guilda, considerando sua história de vida criptobiótica ou hipogeica, com espécies da Região Neotropical variando de 0,4 a 6 mm (DASH, 2011). Espécies de Gnamptogenys comumente coletadas na serapilheira são incluídas nesta macroguilda, como, por exemplo, G. annulata, G. continua e
G. reichenspergeri (LATTKE, 1995). Espécies de Pseudoponera morfologicamente similares a Hypoponera (por exemplo, Pseudoponera gilberti, P. lenkoi, P. stigma) ou outras espécies de Ponerinae relativamente pequenas de serapilheira (Neoponera bucki e Rasopone ferruginea, por exemplo) são classificadas neste grupo. Em geral, essas espécies têm tamanho de corpo relativo maior que a maioria das espécies de Hypoponera. O grupo é predador generalista, atacando uma ampla diversidade de itens, como outros artrópodes em geral (imaturos ou adultos), assim como adultos de formigas.

\section{Poneríneos grandes predadores epigei- cos solitários}

Caracterizado pela presença de espécies de tamanho relativo grande (entre as maiores espécies de formigas Neotropicais conhecidas), como as de Dinoponera e algumas espécies de Pachycondyla. Operárias forrageiam isoladamente à procura de presas; são oportunamente saprófagas de carcaças de artrópodes e cadáveres de pequenos mamíferos; além de predadores oportunistas de cupins em alguns casos (BRANDÃO et al., 2009). Pachycondyla crassinoda forrageia também na serapilheira, sendo predadora oportunista de vários gêneros de cupins (MACKAY; MACKAY, 2010). Pachycondyla harpax e P. striata, comuns em diversos ecossistemas, são predadores generalistas e têm em sua dieta o uso de lipídeos de sementes. Esta guilda inclui ainda Pachycondyla impressa, outra espécie de tamanho grande, encontrada em várias formações vegetais da Região Neotropical, incluindo pastagens e florestas. Dinoponera australis (Figura 13.2) e Dinoponera quadridens, atraídas facilmente a iscas de sardinha, visitam também carcaças de 
anfíbios e répteis e são capazes de predar espécies de tamanho pequeno desses grupos.

\section{Ectaheteromorfos predadores generalistas}

Em função da sua posição filogenética, consideramos Ectatomma, algumas Gnamptogenys e algumas Heteroponera de tamanho médio $(H$. dentinodis, $H$. inca) a grande $(H$. dolo, H. monticola, $H$. robusta), predadoras generalistas, separadas da guilda anterior. Algumas espécies de
Heteroponera e Gnamptogenys vivem na serapilheira, mostrando hábitos diurnos e tímidos (por exemplo, H. dolo; FEITOSA, 2011). Em especial, as espécies de Ectatomma são generalistas e oportunamente saprófagas, forrageando no solo e em arbustos por artrópodes, anelídeos e restos orgânicos; coletam também excesso de exsudatos açucarados de membracídeos e outros Hemiptera, de nectários extraflorais ou adquirem substâncias líquidas de frutos (ARIAS-PENNA, 2008). Diferentemente, E. opaciventre (Figura 13.3) parece

Figura 13.2. Poneríneos grandes predadores epigeicos solitários. Uma operária de Dinoponera australis na entrada do ninho. Local: Fazenda Arco Íris, Serra da Bodoquena, MS (Foto: Paulo Robson de Souza).

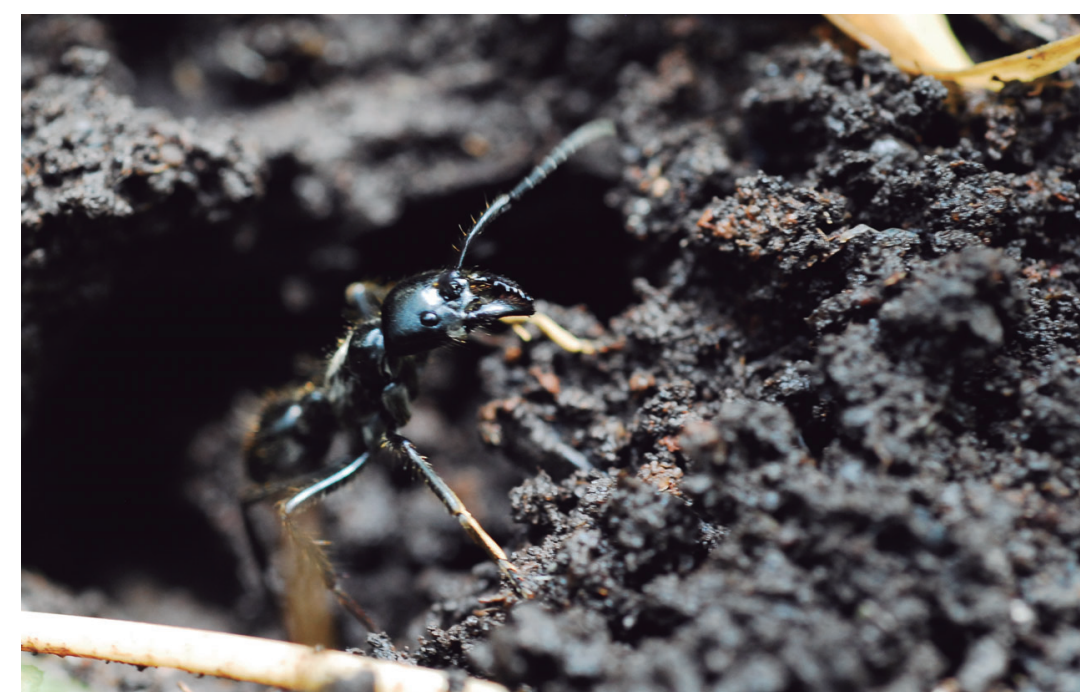

Figura 13.3. Ectaheteromorfos predadores generalistas: Ectatomma opaciventre arrastando um indivíduo morto de Camponotus rufipes e a formiga Ectatomma planidens (menor) tentando roubar o recurso alimentar (cleptoparasitismo). Local: Cerrado stricto senso, Pantanal de Nhecolância, Corumbá, MS (Foto: Paulo Robson de Souza).

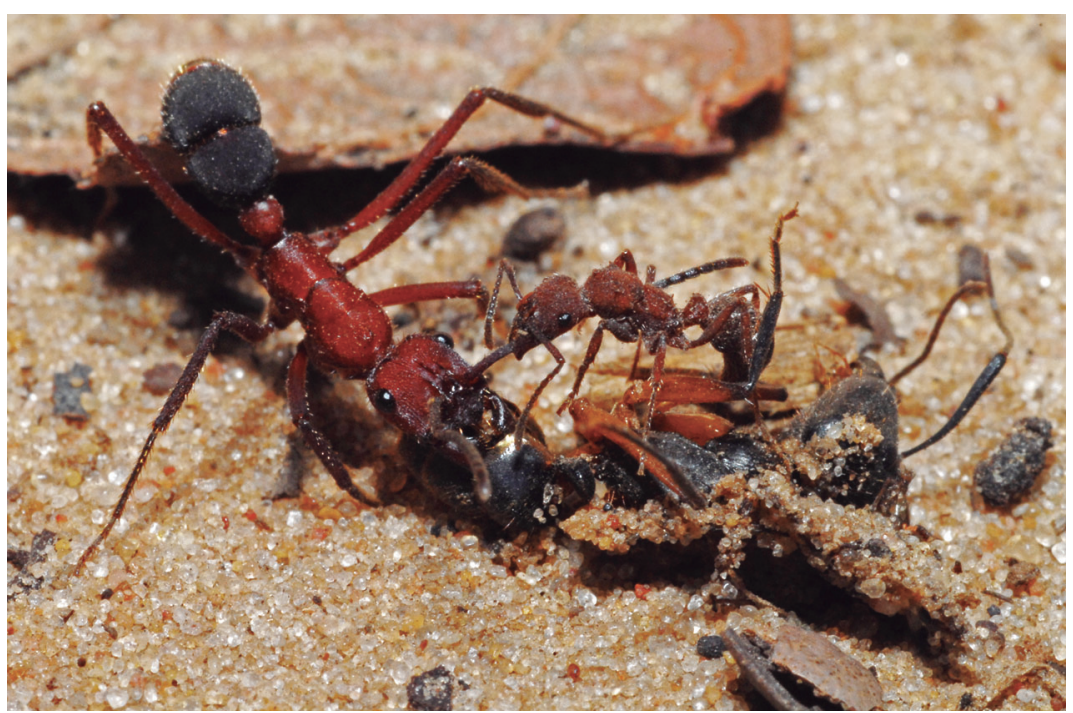


não usar substâncias líquidas e açucaradas, predando principalmente cupins e formigas cortadeiras (Acromyrmex e Atta) (PIE, 2004). De fato, algumas espécies de Ectatomma têm sua dieta composta por alados e operárias de formigas (WHEELER, 1986; PAIVA; BRANDÃO, 1989; LACHAUD et al., 1996), inclusive no período noturno. A maioria das espécies de Gnamptogenys, como G. striatula, G. gracilis e G. moelleri, são reconhecidamente predadores epigeicos generalistas, incluindo em sua dieta larvas de Diptera e adultos de Coleoptera, Collembola e Thysanura (LATTKE, 1995); G. moelleri tem uma significativa base da dieta formada por animais mortos e algumas operárias podem coletar néctar extrafloral (COGNI; OLIVEIRA, 2004).

\section{Poneromorfos com atividade arborícola}

Entre os poneromorfos, várias espécies têm um modo de vida inteiramente arborícola, como é o caso de algumas espécies de Gnamptogenys, Neoponera, Ectatomma, Platythyrea, Anochetus e Acanthoponera. Incluímos aqui apenas as espécies que têm biologia por excelência arborícola, o que significa localização do ninho e forrageamento restrito à vegetação. Por exemplo, G. conccina, consistentemente observada e coletada em árvores onde nidifica, predando artrópodes em geral (DELABIE et al., 2010);
G. pleurodon prefere cavidades pré-existentes de plantas, forrageando em árvores e arbustos (LATTKE, 1995). Anochetus hohenbergiae é a maior espécie do seu gênero ( $>12,70 \mathrm{~mm})$, nidifica em bromélias epífitas de dossel no Nordeste do Brasil (FEITOSA et al., 2012); algumas espécies de Neoponera são reconhecidamente arborícolas (MACKAY; MACKAY, 2010; FERNANDES et al., 2014). Neoponera villosa nidifica em árvores (Figura 13.4), mas forrageia tanto no solo quanto na vegetação, de dia e de noite, buscando nectários extraflorais e substâncias açucaradas de afídeos e pode carregar gotas de líquido entre as mandíbulas (PAUL; ROCES, 2003), comportamento compartilhado com Odontomachus haematodus (DELABIE, 2001) e Platythyrea (DE ANDRADE, 2004). Neoponera crenata e N. unidentata usam várias espécies de plantas como local de construção de ninhos; outras espécies nidificam exclusivamente em plantas mirmecófitas do gênero Cecropia (Neoponera insignis, $N$. luteola e $N$. fisheri) (MACKAY; MACKAY, 2010; SCHMIDT; SHATTUCK, 2014). Espécies de Acanthoponera são coletadas ou observadas em vegetação mais frequentemente no período noturno; o conhecimento sobre a história natural de suas espécies é incipiente (FEITOSA, 2011), assim como das espécies de Heteroponera que parecem ter uma preferência pelo estabelecimento de suas colônias em árvores e arbustos; esse é o caso de H. inermis

Figura 13.4. Neoponera villosa, poneromorfa com atividade arborícola, nidificando em uma árvore morta. Local: Fazenda Califórnia, Serra da Bodoquena, MS (Foto: Paulo Robson de Souza).

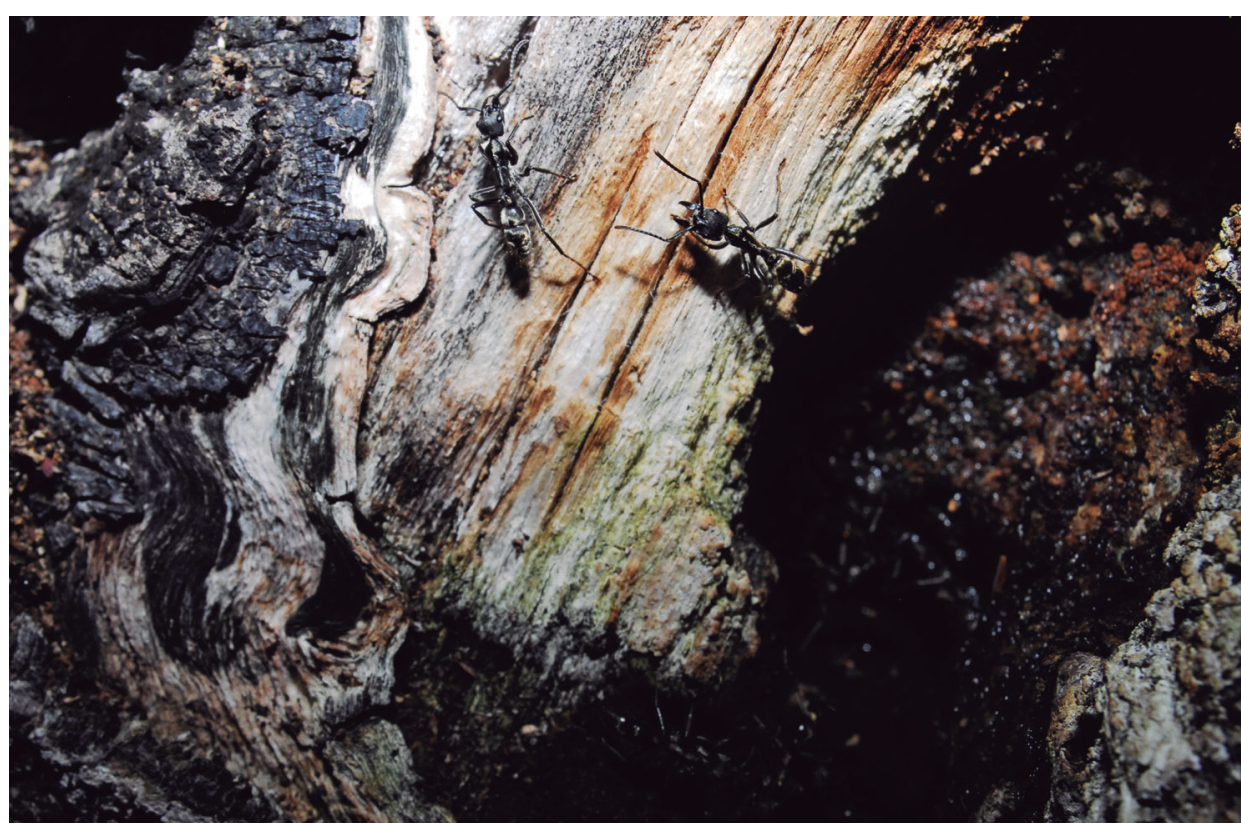


Figura 13.5. Poneromorfos com atividade arborícola: Paraponera clavata explorando nectário floral de Pseudobombax (Malvaceae) de noite. Local: Cerrado da UFMS, Campo Grande, MS (Foto: Paulo Robson de Souza).

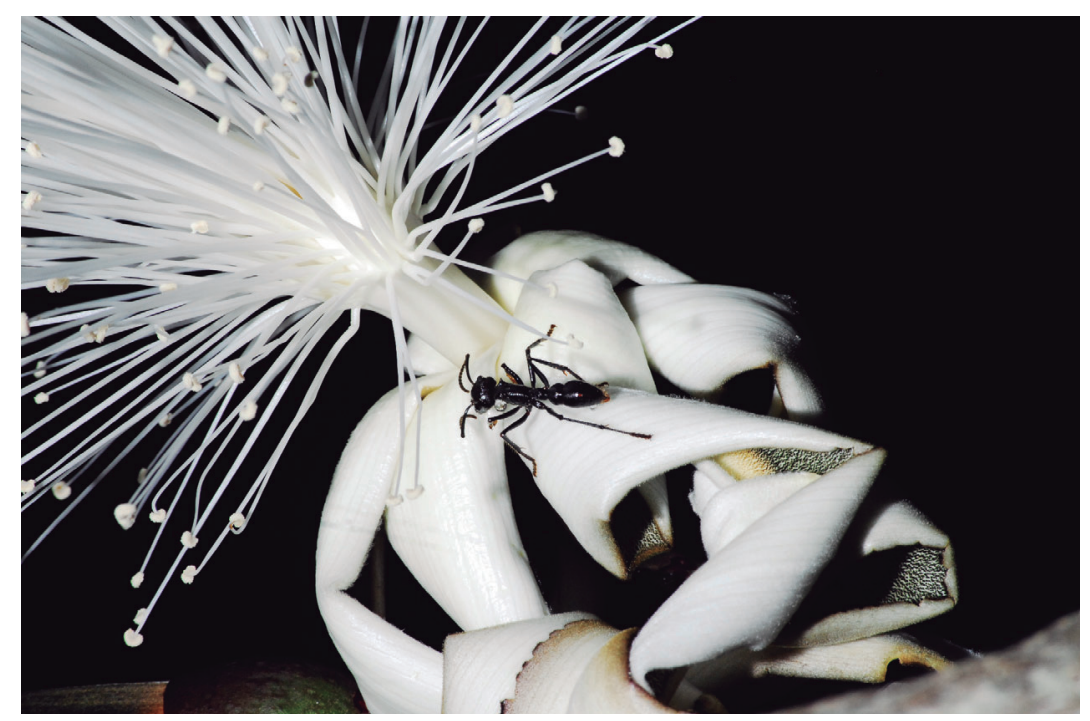

Figura 13.6. Uma operária de Ectatomma tuberculatum que exibe forrageamento predominantemente na vegetação, explorando nectário floral. Local: Floresta ripária do Rio Paraguai, Serra do Amolar, Pantanal, MS (Foto: Paulo Robson de Souza).

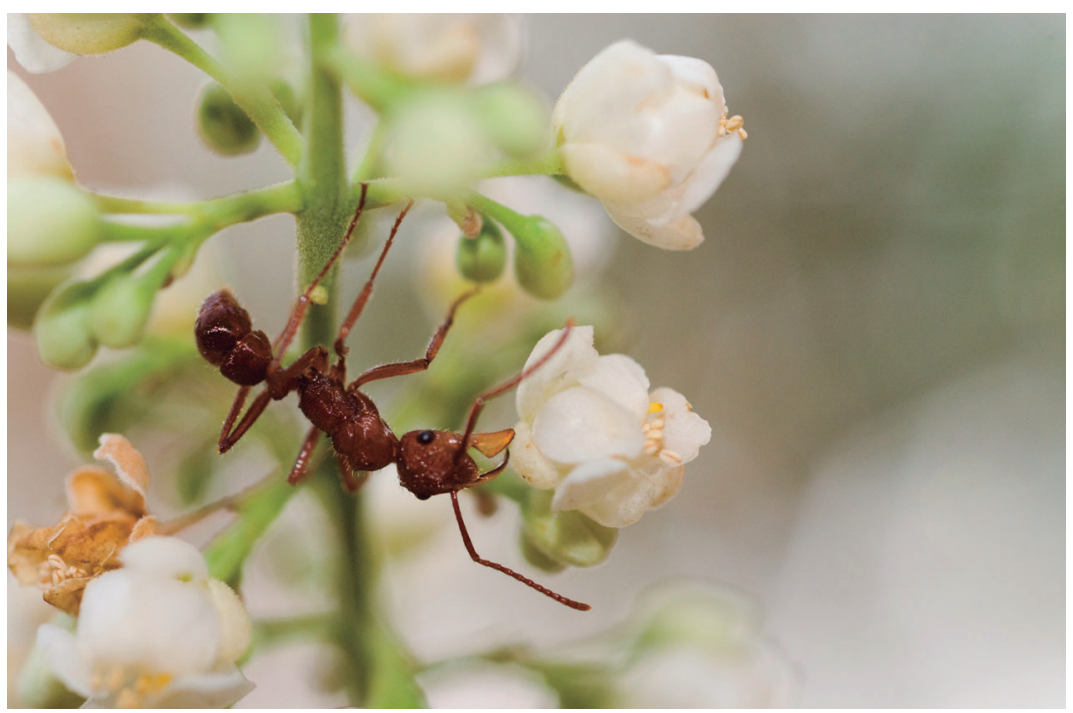

e H. panamensis (FEITOSA, 2011). Adicionamos a esse grupo também Paraponera clavata (Figura 13.5) e E. tuberculatum (Figura 13.6) que exibem forrageamento predominantemente na vegetação, se alimentando de nectários. Algumas espécies de Hypoponera, Anochetus hohenbergiae (FEITOSA et al., 2012), Odontomachus hastatus (CAMARGO; OLIVEIRA, 2012) e Anochetus mayri (LONGINO, 2010), por exemplo, exploram a interface raiz-vegetação de epífitas arbóreas.

\section{Poneríneos com mandíbulas longas}

Odontomachus e algumas Anochetus formam um grupo caracterizado pelo grande tamanho de corpo e as mandíbulas lineares relativamente longas, representando alguns dos maiores predadores do solo e serapilheira. Reúne espécies predadoras equipadas com mandíbulas que apresentam movimento de fechamento extremamente rápido, chamadas de mandíbulas armadilha, adaptadas 
para predação, ficando paralelas quando fechadas e com abertura de 180 graus quando estão buscando presas. Esse mecanismo surgiu independentemente em três subfamílias (ou quatro vezes na história evolutiva de Formicidae): nos gêneros poneríneos Odontomachus e Anochetus, no gênero extratropical formicíneo Myrmoteras e na tribo Dacetini (Myrmicinae - sensu BOLTON, 2003) (LARABEE; SUAREZ, 2014). Odontomachus possui comportamento agressivo em relação às outras espécies que visitam a mesma fonte de alimento; frequentemente outros indivíduos são recrutados na colônia por tandem running na tentativa de dominância de recursos alimentares.

\section{Poneríneos crípticos especializados}

Incluímos aqui uma grande diversidade de formas, reunindo espécies pouco estudadas, com morfologia muito modificada sugerindo uso especializado de recursos. Há espécies de tamanho relativo médio a pequenas, mandíbulas estreitas e com pontos de articulação distantes entre si, com dentição diferenciada (com é o caso de Stigmatomma com duplo alinhamento de dentes na mandíbula), alguns gêneros com dentes clipeais (é o caso de Stigmatomma, Prionopelta e alguns Typhlomyrmex), olhos próximos ou distantes da inserção da mandíbula, distantes entre si, reduzidos ou ausentes.

Entre os proceratiíneos, há indicações na literatura que Discothyrea preda ootecas de aranhas (BROWN, 1958; LEVIEUX, 1977; DEJEAN; DEJEAN, 1998), enquanto Probolomyrmex e Proceratium são especializados em ovos de artrópodes (TAYLOR, 1965; BROWN, 1975, 1980; BARONI URBANI; DE ANDRADE, 2003). Amblioponíneos do gênero Prionopelta são especializados em dipluros campodeídeos e Stigmatomma em Myriapoda. Alguns poneríneos, como Centromyrmex, são especializados em cupins (KEMPF, 1966; DELABIE, 1995), Thaumatomyrmex em miriápodes Polyxenidae (BRANDÃO et al., 1991; EISNER et al., 1996; JAHYNY et al., 2008; RABELLING et al., 2012), Belonopelta em dipluros (WILSON, 1955) e Leptogenys em isópodes terrestres (LENKO, 1966; DEJEAN; EVRAERTS, 1997). Entre os ectatommíneos, espécies do grupo rastrata de Gnamptogenys, são especializadas em diplópodes, G. banksi preda miriápodes, $G$. hartmanni preda coleópteros, G. horni preda outras formigas e G. bruchi caça formigas do gênero
Trachymyrmex (LATTKE, 1995); Typhlomyrmex meire preda imaturos de Acropyga fuhrmanni (LACAU et al., 2004).

Não há informações sobre dieta alimentar dos Probolomyrmex neotropicais, somente algumas observações comportamentais de P. boliviensis (TAYLOR, 1965), mas em função do elevado número de glândulas epidérmicas, essas formigas provavelmente apresentam atividade especializada (Lacau, com. pessoal).

\section{Poneríneos com biologia semi-nômade} e forrageamento em colunas

\section{Leptogenys e Simopelta adotam} forrageamento em densas colunas de ataque, buscando presas, bem como algumas síndromes de formigas legionárias (deslocamento constante do ninho, incluindo transporte de imaturos, e produção sincronizada da prole). Simopelta ataca principalmente Pheidole e ocasionalmente Stenamma (Myrmicinae), sendo mais comuns na Costa Rica, em altitudes intermediárias (cerca de $1.500 \mathrm{~m})$ (LONGINO, 2010). Neoponera marginata emprega colunas de ataque e preda cupins do gênero Neocapritermes, enquanto N. commutata preda cupins do gênero Syntermes (MACKAY; MACKAY, 2010). Leptogenys é considerada seminômade porque mudanças de ninho para outras áreas foram observadas em campo em mais de uma oportunidade, quando as operárias carregam ovos e pupas.

A importância das guildas nos estudos sobre estrutura morfológica da fauna de formigas e processos funcionais nos ecossistemas

Um inventário faunístico qualificado e uma taxonomia refinada são pré-requisitos essenciais para a compreensão dos processos ecológicos de ecossistemas. Inferimos aqui que a filogenia está relacionada intimamente à ecologia funcional, uma vez que guildas ancestrais foram se diversificando e mudando o cenário ecológico da comunidade conforme a adaptação das espécies a outros nichos. A evolução das guildas pode ser uma repetição do processo de especiação por cladogênese e, ao longo do tempo, grupos funcionais são extintos e outros criados.

As formigas poneromorfas são, sem dúvida, mais diversas em áreas íntegras de fisionomias florestadas, reflexo da particularidade na composição 
de espécies por área amostrada e por um número relativamente alto de espécies representadas por poucos indivíduos, principalmente quando são utilizadas técnicas de amostragem como extratores Winkler, pitfall, iscas e coletas ativas qualitativas. O impacto das populações de poneromorfas na estrutura da comunidade ainda é pouco avaliado e poucos estudos adotam abordagens que permitam esta avaliação, como o que foi verificado para $P$. striata e Odontomachus chelifer que produzem um importante aporte na produção de sementes de árvores de florestas pluviais devido à alta concentração de nutrientes ao redor do ninho (PASSOS; OLIVEIRA, 2002).

Deve-se aprimorar a classificação da comunidade em guildas nos estudos de ecologia evolutiva e biogeográfica, para que a abordagem funcional de ecossistemas não seja feita de forma superficial. A presente proposta integra dados sobre grupos tróficos (carnívoras, nectarívoras, detritívoras ou onívoras), síndromes comportamentais (agressivas, subordinadas, oportunistas, ágeis ou parasitas), distribuição espacial no hábitat (arborícolas, serapilheira, superfície e subterrâneas), forma de recrutamento (patrulheiras, focais, crípticas ou nômades), reprodutivas (monogínicas, políginicas, ergatoides, microgines e populações clones) e morfométricas (tamanho relativo de corpo, olhos e mandíbulas) para delimitar macroguildas. $\mathrm{O}$ uso deste modelo conceitual permite também a delimitação de microguildas em estudos locais de comunidades, descrevendo de forma elaborada e adequada a organização da fauna de formigas em diferentes áreas da Região Neotropical. Consideramos isto importante porque pode ocorrer sobreposição entre espécies de macroguildas diferentes, determinada pelo extenso repertório da biologia das formigas. Operárias de muitas espécies de poneromorfas comuns nas florestas tropicais patrulham constantemente a área próxima ao ninho em busca de invertebrados vivos ou mortos, frutos, fezes de vertebrados e substâncias açucaradas; há espécies que modificam o uso dos recursos ao longo do ano (RAIMUNDO et al., 2009). Análises de estruturação morfológica sugerem certa sobreposição entre algumas guildas (SILVA; BRANDÃO, 2010), mas faltam estudos intra-guilda descrevendo padrões sazonais de uso dos recursos e eventuais mudanças de biologia trófica.

Cada guilda tem sua importância dentro das comunidades, em função da sua contribuição para os fluxos de energia e biomassa nos sistemas ecológicos; quantificar e descrever a relação entre atributos morfológicos-fisiológicos e o papel funcional das formigas no diferentes ecossistemas pode ser fundamental para a biologia da conservação; considerar a estrutura da comunidade em guildas é uma importante ferramenta para atingir este objetivo.

\section{Referências}

ARIAS-PENNA, T. M. Subfamilia Ectatomminae. In: JIMÉNEZ, E.; FERNÁNDEZ, F.; ARIAS, T. M.; LOZANO-ZAMBRANO, F. H. (Eds). Sistematica, Biogeografia y Conservación de las Hormigas Cazadoras de Colombia. Instituto Alexander von Humboldt, Bogota, 2008, p. 53-107.

BARONI URBANI, C.; DE ANDRADE, M. L. The Ant Genus Proceratium in the Extant and Fossil Record (Hymenoptera: Formicidae). Torino:

Museo Regionale di Scienze Naturali, 2003, 492 p. (Monografie, 36).

BLAUM, N.; MOSNER, E.; SCHWAGER, M.; JELTSCH, F. How functional is functional? Ecological groupings in terrestrial animal ecology: towards an animal functional type approach.

Biodiversity and Conservation, London, v.20, p. 2333-2345, 2011.

BLONDEL, J. Guilds or functional groups: does it matter? Oikos, Copenhagen, v. 100, p. 223-231, 2003.

BLONDER, B.; LAMANNA, C.; VIOLLE, C.; ENQUIST, B. J. The n-dimensional hypervolume. Global Ecology and Biogeography: A journal of Macroecology, Oxford, v. 23, p. 595-609, 2014.

BOLTON, B. 2003. Synopsis and Classification of Formicidae. Gainesville: American Entomological Institute. p. 1-370 (Memoirs of the American Entomological Institute, 71), 2003.

BRADY, S. G.; SCHULTZ, T. R.; FISHER, B. L.; WARD, P. S. Evaluating alternative hypotheses for the early evolution and diversification of ants. Proceedings of the National Academy of Sciences of the United States of America, Washington, DC, v. 103, p. 1817218177, 2006.

BRANDÃO, C. R. F.; DINIZ, J. L. M.; TOMOTAKE, M. E. Thaumatomyrmex strips millipedes for prey, a novel predatory behaviour in ants and the first case of sympatry in the genus. Insectes Sociaux, Basel, v. 38, p. 335-344, 1991. 
BRANDÃO, C. R. F.; SILVA, R. R.; DELABIE, J. H. C. Formigas (Hymenoptera). In: PANIZZI, A. R.; PARRA, J. R. P. (Eds.). Bioecologia e Nutrição de Insetos: Base para o Manejo Integrado de Pragas. Embrapa Informação Tecnológica, Brasília, DF, 2009, p. 323-370.

BRANDÃO, C. R. F.; SILVA, R. R.; DELABIE, J. H. C. Neotropical ants (Hymenoptera) functional groups: nutritional and applied implications. In: PANIZZI, A. R.; PARRA, J. R. P. (Eds.). Bioecology and Insect Nutrition. CRC Press, Taylor; Francis Company, 2012, p. 213-236.

BROWN, W. L., Jr. Predation of arthropod eggs by the ant genera Proceratium and Discothyrea. Psyche, Cambridge, v. 64, p. 115, 1958.

BROWN, W. L., Jr. Contributions toward a reclassification of the Formicidae. V. Ponerinae, tribes Platythyreini, Cerapachyini, Cylindromyrmecini, Acanthostichini, and Aenictogitini. Search Agriculture: entomology, Ithaca, v. 5, p. 1-115, 1975.

BROWN, W. L., Jr. A remarkable new species of Proceratium, with dietary and other notes on the genus (Hymenoptera: Formicidae). Psyche, Cambridge, v. 86, p. 337-346, 1980.

CAMARGO, R. X.; OLIVEIRA, P. S. Natural history of the neotropical arboreal ant, Odontomachus hastatus: nest sites, foraging schedule, and diet. Journal of Insect Science, Tucson, v. 12, p. 48, 2012.

CHASE, J. M.; LEIBOLD, M. A. Ecological Niches: Linking Classical and Contemporary Approaches. Chicago, IL. University of Chicago Press, 2003, 212 p.

COGNI, R.; OLIVEIRA, P. S. Patterns in foraging and nesting ecology in the neotropical ant Gnamptogenys moelleri (Formicidae, Ponerinae). Insectes Sociaux, Basel, v. 51, p. 123-130, 2004.

COLWELL, R. K.; RANGEL, T. F. Hutchinson's duality: the once and future niche. Proceedings of the National Academy of Sciences of the United States of America, Washington, DC, v. 106, p. 19651-19658, 2009.

DASH, S. T. A taxonomic revision of the New World Hypoponera Santschi, 1938 (Hymenoptera: Formicidae). University of Texas, El Paso, Ph.D thesis. 2011, 277 p.

DAVIDSON, D. W. Ecological stoichiometry of ants in a New World rain forest. Oecologia, Berlin, v. 142, p. 221-231, 2005.

DAVIDSON, D. W.; COOK, S. C.; SNELLING, R. R.; CHUA, T. H. Explaining the abundance of ants in lowland tropical rainforest canopies. Science, Washington, DC, v. 300, p. 969-972, 2003.
DE ANDRADE, M. L. A new species of Platythyrea from Dominican amber and description of a new extant species from Honduras. Revue Suisse de Zoologie, Genève, v. 111, p. 643-655, 2004.

DE PAULA, G. A. R. Perspectiva histórica e estudo de conceitos em ecologia funcional. Oecologia Australis, Rio de Janeiro, v.17, p. 331-346, 2013.

DEJEAN, A.; DEJEAN, A. How a ponerinae ant acquired the most evolved mode of colony foundation. Insectes Sociaux, Basel, v. 45, p. 343-346, 1998.

DEJEAN, A.; EVRAERTS, C. Predatory behavior in the genus Leptogenys: a comparative study. Journal of Insect Behavior, New York, v. 10, p. 17-191, 1997.

DELABIE, J. H. C. Inquilinismo simultâneo de duas espécies de Centromyrmex (Hymenoptera; Formicidae; Ponerinae) em cupinzeiros de Syntermes sp (Isoptera; Termitidae; Nasutermitinae). Revista Brasileira de Entomologia, Curitiba, v. 39, p. 605-609, 1995.

DELABIE, J. H. C. Trophobiosis between Formicidae and Hemiptera (Sternorrhyncha and Auchenorrhyncha): an overview. Neotropical Entomology, Londrina, v. 30, p. 501-516, 2001.

DELABIE, J. H. C.; AGOSTI, D.; NASCIMENTO, I. C. Litter ant communities of the Brazilian Atlantic rain forest region. In: AGOSTI, D.; MAJER, J. D.; ALONSO, L. E.; SCHULTZ, T. (Eds.). Sampling ground-dwelling ants: case studies from the world's rain forests. Perth, Australia, Curtin University School of Environmental Biology, Bulletin, No. 18, 2000, p. 1-17.

DELABIE, J. H. C.; DA ROCHA, W. D.; FEITOSA, R. M.; DEVIENNE, P.; FRESNEAU, D. Gnamptogenys concinna (F. Smith, 1858): nouvelles données sur sa distribution et commentaires sur ce cas de gigantisme dans le genre Gnamptogenys (Hymenoptera, Formicidae, Ectatomminae). Bulletin de la Société entomologique de France, Paris, v. 115, p. 269-277, 2010.

DIAMOND, S. E.; NICHOLS, L. M.; MCCOY, N.; HIRSCH, C.; PELINI, S. L.; SANDERS, N. J.; ELLISON, A. M.; GOTELLI, N. J.; DUNN, R. R. A physiological trait-based approach to predicting the responses of species to experimental climate warming. Ecology, Durham, v. 93, p. 2305-2312, 2012.

ELTON, C. S. Animal Ecology. University of Chicago Press. 1927, 209p.

EISNER, T.; EISNER, M.; DEYRUP, M. Millipede defense: use of detachable bristles to entangle ants. Proceeding of the National Academy of Sciences of the United States of America, Washington, DC, v. 93, p. 10848-10851, 1996. 
FARIAS, A. A.; JAKSIC, F. M. Assessing the relative contribution of functional divergence and guild aggregation to overall functional structure of species assemblages. Ecological Informatics, Amsterdam, v. 1, p. 367-375, 2006.

FEITOSA, R. M. Revisão taxonômica e análise filogenética de Heteroponerinae (Hymenoptera, Formicidae). Universidade de São Paulo, FFCLRP, Departamento de Biologia, Programa de Pós-Graduação em Entomologia. Tese de Doutorado, 2011, 297 p.

FEITOSA, R. M.; HORA, R. R.; DELABIE, J. H. C.; VALENZUELA, J.; FRESNEAU, D. A new social parasite in the ant genus Ectatomma F. Smith (Hymenoptera, Formicidae, Ectatomminae). Zootaxa, Auckland, v. 1713, p. 47-52, 2008.

FEITOSA, R. M.; LACAU, S.; DA ROCHA, W. D.; OLIVEIRA, A. R.; DELABIE, J. H. C. A giant new arboreal species of the ant genus Anochetus from Brazil (Formicidae: Ponerinae). Annales de la Société Entomologique de France, Paris, v. 48, p. 253-259, 2012.

FERNANDES, I. O.; DE OLIVEIRA, M. L.; DELABIE, J. H. C. Description of two new species in the Neotropical Pachycondyla foetida complex (Hymenoptera: Formicidae: Ponerinae) and taxonomic notes on the genus. Myrmecological News, Vienna, v. 19, p. 133-163, 2014.

FERNÁNDEZ, F. C.; ARIAS-PENNA, T. M. Las hormigas cazadoras en la región Neotropical. In: JIMÉNEZ, E.; FERNÁNDEZ, F.; ARIAS, T. M.; LOZANO-ZAMBRANO, F. H. (Eds). Sistematica, Biogeografia y Conservación de las Hormigas Cazadoras de Colombia. Instituto Alexander von Humboldt, Bogota, 2008, p. 3-40.

\section{GOTELLI, N. J.; GRAVES, G. R. Null Models in} Ecology. Smithsonian Institution Press, Washington, DC, 1996, $368 \mathrm{p}$.

GRINNELL, J. The niche-relationships of the California thrasher. Auk, Washington, v. 34, p. 427-433, 1917.

HOLT, R. D. Bringing the Hutchinsonian niche into the 21st century: ecological and evolutionary perspectives. Proceedings of the National Academy of Sciences of the United States of America, Washington, DC, v. 106, p. 19659-19665, 2009.

HORA, R. R.; DOUMS, C.; POTEAUX, C.; FÉNÉRON, R.; VALENZUELA, J.; HEINZE, J.; FRESNEAU, D. Small queens in the ant Ectatomma tuberculatum: a new case of social parasitism. Behavioral Ecology and Sociobiology, Berlin, v. 59, p. 285-292, 2005.
HUTCHINSON, G. E. Concluding remarks: Cold Spring Harbor symposium. Quantitative Biology, Cold Spring Harbor NY, v. 22, p. 415-427, 1957.

JACKSON, A. L.; INGER, R.; PARNELL, A. C.; BEARSHOP, S. Comparing isotopic niche widths among and within communities: SIBER - Stable Isotope Bayesian Ellipses in R. Journal of Animal Ecology, Oxford, v. 80, p. 595-602, 2011.

JAHYNY, B.; LACAU, S.; DELABIE, J. H. C.; FRESNEAU, D. Le genre Thaumatomyrmex Mayr 1887, cryptique et prédateur spécialiste de Diplopoda Penicillata. In: JIMÉNEZ, E.; FERNÁNDEZ, F.; ARIAS, T. M.; LOZANO-ZAMBRANO, F. H. (Eds). Sistematica, Biogeografia y Conservación de las Hormigas Cazadoras de Colombia. Instituto Alexander von Humboldt, Bogota, 2008, p. 329-346.

JAKSIC, F. M. Abuse and misuse of the term "guild" in ecological studies. Oikos, Copenhagen, v. 37, p. 397 400, 1981.

JAKSIC, F. M.; MEDEL, R. G. Objective recognition of guilds: testing for statistically significant species clusters. Oecologia, Berlin, v. 82, p. 87-92, 1990.

JIMÉNEZ, E.; FERNÁNDEZ, F. T. M.; LOZANOZAMBRANO, F. H. (Eds.). Sistemática, Biogeografía y Conservación de las Hormigas cazadoras de Colombia. Instituto de Investigación de Recursos Biológicos Alexander von Humboldt, Bogotá, 2008, 609 p.

KASPARI, M. Taxonomic level, trophic biology and the regulation of local abundance. Global Ecology and Biogeography: a journal of macroecology, Oxford, v. 10, p. 229-244, 2001.

KEARNEY, M.; SIMPSON, S. J.; RAUBENHEIMER, D.; HELMUTH, B. 2010. Modelling the ecological niche from functional traits. Philosophical Transactions of the Royal Society B, London, v. 365, p. 3469-3483.

KEMPF, W. W. A synopsis of the neotropical ants of the genus Centromyrmex Mayr (Hymenoptera: Formicidae). Studia Entomologica, Petropólis, v. 9, p. 401-410, 1966.

LACAU, S., VILLEMANT, C.; DELABIE, J. H. C. Typhlomyrmex meire, a remarkable new species endemic to Southern Bahia, Brazil (Formicidae: Ectatomminae).

Zootaxa, Auckland, v. 687, p. 1-23, 2004.

LACHAUD, J. P.; LÓPEZ-MÉNDEZ, J. A.; SCHATZ, B.; DE CARLI, P.; BEUGNON, G. Comparaison de l'impact de prédation de deux ponérines du genre Ectatomma dans un agroécosystème néotropical. Actes des Colloques Insectes Sociaux, Paris, v. 10, p. 67-74, 1996. 
LANAN, M. Spatiotemporal resource distribution and foraging strategies of ants (Hymenoptera: Formicidae). Myrmecological News, Vienna, v. 20, p. 53-70, 2014.

LARABEE, F. J.; SUAREZ, A. V. The evolution and functional morphology of trap-jaw ants (Hymenoptera: Formicidae). Myrmecological News, Vienna, v. 20, p. 25-36, 2014.

LATTKE, J. E. Revision of the ant genus Gnamptogenys in the New World (Hymenoptera: Formicidae).

Journal of Hymenoptera Research, Washington, DC, v. 4, p. 137-193, 1995.

LENKO, K. A formiga Leptogenys bohlsi como predadora de isopodos (Hymenoptera: Formicidae). Papeis Avulsos de Zoologia, São Paulo, v. 19, p. 59-61, 1966.

LEVIEUX, J. La nutrition des fourmis tropicales. V. Elements de synthese: les modes d'exploitation de la biocenose. Insectes Sociaux, Basel, v. 24, p. 235-260, 1977.

LONGINO, J. T. Ants of Costa Rica. 2010. Disponível em: http://www.evergreen.edu/ants/AntsofCostaRica. html. Acesso em: 30 Maio de 2014.

MCGILL, B. J., ENQUIST, B., WEIHER, E.; WESTOBY, M. Rebuilding community ecology from functional traits. Trends in Ecology and Evolution, Cambridge, v. 21, p. 178-185, 2006.

MACKAY, W. P.; MACKAY, E. E. The systematics and biology of the New World ants of the genus Pachycondyla (Hymenoptera: Formicidae). Edwin Mellon Press, Lewiston, 2010.642 p.

MOREAU, C. S.; BELL, C. D.; VILA, R.; ARCHIBALD, S. B.; PIERCE, N. E. Phylogeny of the ants: diversification in the age of angiosperms. Science, Washington, DC, v. 312, p. 101-104, 2006.

MORGAN, E. D.; JUNGNICKEL, H.; KEEGANS, S. J.; NASCIMENTO, R. R.; BILLEN J.; GOBIN B.; ITO, F. Comparative survey of abdominal gland secretions of the ant subfamily Ponerinae. Journal of Chemical Ecology, New York, v. 29, p. 95-114, 2003.

NEWSOME, S. D.; DEL RIO, C. M.; BEARSHOP, S.; PHILLIPS, D. L. A niche for isotopic ecology. Frontiers in Ecology and Environment, Washington, DC, v. 5, p. 429-436, 2007.

PAIVA, R. V. S.; BRANDÃO, C. R. F. Estudos sobre a organização social de Ectatomma permagnum Forel, 1908 (Hymenoptera, Formicidae). Revista Brasileira de Biologia, São Carlos, v. 49, p. 783-792, 1989.
PASSOS, L.; OLIVEIRA, P. S. Ants affect the distribution and performance of Clusia criuva seedlings, a primarily bird-dispersed rainforest tree. Journal of Ecology, London, v. 90, p. 517-528, 2002.

PASSOS, L.; OLIVEIRA, P. S. Interaction between ants and fruits of Guapira opposita (Nyctaginaceae) in a Brazilian sandy plain rainforest: ant effects on seeds and seedlings. Oeologia, Berlin, v. 139, p. 376-382, 2004.

PAUL, J.; ROCES, F. Fluid intake rates in ants correlate with their feeding habits. Journal of Insect Physiology, Oxford, v. 49, p. 347-357, 2003.

PEETERS, C. Convergent evolution of wingless reproductives across all subfamilies of ants, and sporadic loss of winged queens (Hymenoptera: Formicidae).

Myrmecological News, Vienna, v. 16, p. 75-91, 2012.

PIANKA, E. R. Guild structure in desert lizards. Oikos, Copenhagen, v. 35, p. 194-201, 1980.

PIE, M. R. Foraging ecology and behaviour of the ponerine ant Ectatomma opaciventre Roger in a Brazilian savannah. Journal of Natural History, London, v. 38, p. 717-729, 2004.

RABELLING, C.; VERHAAGH, M.; GARCIA, M. V. B. Observations on the specialized predatory behavior of the pitchfork-mandibles ponerine ant Thaumatomyrmex paludis (Hymenoptera: Formicidae). Breviora, United States, v. 533, p. 1-8, 2012.

RAIMUNDO, R. L. G.; FREITAS, A. V. L.; OLIVEIRA, P. S. Seasonal patterns in activity rhythm and foraging ecology in the Neotropical forest-dwelling ant, Odontomachus chelifer (Formicidae, Ponerinae). Annals of the Entomological Society of America, College Park, v. 102, p. 1151-1157, 2009.

ROOT, R. B. The niche exploitation pattern of the Bluegray Gnatcatcher. Ecological Monographs, Durham,v. 37, p. 317-350, 1967.

\section{SCHIMPER, A. F. W. Plant-Geography Upon a Physiological Basis. Oxford, Clarendon Press. 1903, 839 p.}

SCHMIDT, C. A.; SHATTUCK, S. O. The higher classification of the ant subfamily Ponerinae (Hymenoptera: Formicidae), with a review of ponerine ecology and behavior. Zootaxa, Auckland, v. 3817, p. $1-242,2014$.

SILVA, R. R.; BRANDÃO C. R. F. Morphological patterns and community organization in leaf-litter ant assemblages. Ecological Monographs, Durham, v. 80, p. 107-124, 2010. 
SILVA, R. R.; BRANDÃO C. R. F. Ecosystem-wide morphological structure of leaf-litter ant communities along a tropical latitudinal gradient. PLoS One, San Francisco, v. 9, p. e93049, 2014.

SILVESTRE, R.; BRANDÃO, C. R F.; SILVA, R. R. Grupos funcionales de hormigas: el caso de los gremios del Cerrado, Brasil. In: FERNÁNDEZ, F. (Ed.). Introducción a las Hormigas de la Región Neotropical. Bogotá, Instituto Humboldt. p. 113-143, 2003.

SIMBERLOFF, D.; DAYAN, T. The guild concept and the structure of ecological communities. Annual Review of Ecology and Systematics, Palo Alto, v. 22, p. 115-143, 1991.

SOBERÓN, J.; NAKAMURA, M. Niches and distributional areas: Concepts, methods, and assumptions. Proceedings of the National Academy of Sciences of the United States of America, Washington, DC, v. 106, p. 19644-19650, 2009.

TAYLOR, R. W. A monographic revision of the rare tropicopolitan ant genus Probolomyrmex Mayr (Hymenoptera: Formicidae). Transactions of the Royal Entomological Society of London, London, v. 117 , p. 345-365, 1965.
WEBER, N. A. Two common ponerine ants of possible economic significance, Ectatomma tuberculatum (Olivier) and E. ruidum Roger. Proceedings of the Entomological Society of Washington, Washington, DC, v. 48, p. 1-16, 1946.

WHEELER, D. E. Ectatomma tuberculatum foraging biology and association with Crematogaster (Hymenoptera Formicidae). Annals of the Entomological Society of America, Washington, DC, v. 79, p. 300-303, 1986.

WIENS, J. A. The Ecology of Bird Communities: Foundations and Patterns. Cambridge, Cambridge University Press. v.1, 1989, 538 p.

WILSON, E. O. Ecology and behavior of the ant Belonopelta deletrix Mann (Hymenoptera: Formicidae). Psyche, Cambridge, v. 62, p. 82-87, 1955.

WILSON, J. B. Guilds, functional types and ecological groups. Oikos, Copenhagen,v. 86, p. 507-522, 1999. 